\title{
Recommendations for spinal opioids clinical practice in the management of postoperative pain
}

\author{
Borja Mugabure Bujedo ${ }^{1,2^{*}}$ \\ *Correspondence: mugabure@yahoo.es \\ 'Department of Anesthesiology, Critical Care and Pain Medicine, Donostia University Hospital, San Sebastián 20014, Spain. \\ 2Pain Relief Unit, Acute and Chronic Pain Management, Donostia University Hospital, San Sebastián 20014, Spain.
}

\begin{abstract}
Opioids have been considered the strongest option in clinical practice for the treatment of postoperative pain. However, in this setting, the spinal administration of an opioid drug does not always guarantee selective action and segmental analgesia in the spine due to partial reuptake to blood systemic circulation reaching brain receptors. Recent evidence from experimental studies indicates that bioavailability in the spinal cord biophase is negatively correlated with liposolubility, which is higher for hydrophilic opioids, than for lipophilic ones. Clinical guidelines recommend using a mixture of local anesthetic plus a strong opioid to improve the analgesic effect, minimize adverse effects and improve the overall patient's satisfaction. Moreover, sometimes an opioid alone, typically morphine, can be administered to provide a long period of postoperative analgesia for $24 \mathrm{~h}$, or even $48 \mathrm{~h}$ when an extended release epidural formulation is used. In all cases a vigilance protocol must be recommended to prevent either early or delayed respiratory depression.
\end{abstract}

Keywords: Spinal analgesia, epidural opioids, intrathecal opioids, and postoperative pain

\section{Introduction}

Humans have been administering parenteral opioids for many thousands of years in an effort to produce either analgesia or other clinical effects mediated by the central nervous system. However, it was not until the 1970s that we recognized that the analgesic effects of opioids are mediated by opioid binding to the specific receptors located in the brain stem. At about the same time, researches showed that the dose limiting side effects of systemically administered opioids, such as nausea and vomiting, sedation and respiratory depression were also mediated by opioid receptors in the same brain areas. Unfortunately, due to this "co-localization" of opioid receptors mediating either analgesia or side effects, it was physically impossible to separate the analgesic effects from their doselimiting ones when opioids were administered systemically. After its introduction to clinical practice, spinal opioid administration proceeded at a more rapid pace than did our understanding of the basic mechanism governing the spinal cord bioavailability of epidural and intrathecal administered drugs [1].

A Romanian surgeon presented the first published report on opioids for intrathecal anaesthesia using a mixture of cocaine and morphine in 1901 [2]. Neuraxial morphine was used for several years without a known mechanism of action until 1973, when class of highly specific opioid receptors were identified into the spine. Further, it was proven in animal studies that direct spinal application of morphine produced a good degree of analgesia [3]. A great discovery was made when Wang et al., successfully used intrathecal morphine bolus dose injection in humans [4], and with the publication by Behar et al., in The
Lancet in 1979, the first paper on the use of $2 \mathrm{mg}$ epidural morphine administered as bolus for the treatment of acute and chronic pain. It was suggested that the analgesic effects were mediated by morphine joining specific receptors placed into the posterior dorsal medullar horn [5]. From then until the present, scientific community has focused a great effort on identifying which types of opioids are suitable for spinal use and which are not. While spinal opioid administration can clearly be an effective analgesic technique, there is a widespread misconception that any opioid administered epidural or intratecally will always produce analgesia by a selective spinal mechanism. This is not absolutely the truth, because several opioids that are commonly administered spinally can also produce early analgesia by uptake into the systemic circulation, with subsequent redistribution to brainstem opioid receptors. This is more applicable for lipophilic ones because their minimum analgesic concentration (MEAC) is too low and it can be easily reached in plasma after neuraxial administration $(0.03 \mathrm{ng} / \mathrm{ml}$ for sufentanil and $0.63 \mathrm{ng} / \mathrm{ml}$ for fentanyl). Therefore in some cases, the analgesia produced could be not superior to that produced by intravenous (IV) administration. On the other hand, hydrophilic opioids, like morphine (MEAC 9-30 $\mathrm{ng} / \mathrm{ml}$ ) remain enough time into cerebrospinal fluid (CSF) for cephalic recirculation to produce delayed either analgesia or adverse effects $[6,7]$.

\section{Spinal cord bioavailability}

Despite above-mentioned, spinal opioid administration can still be an excellent way to separate the desirable analgesic 


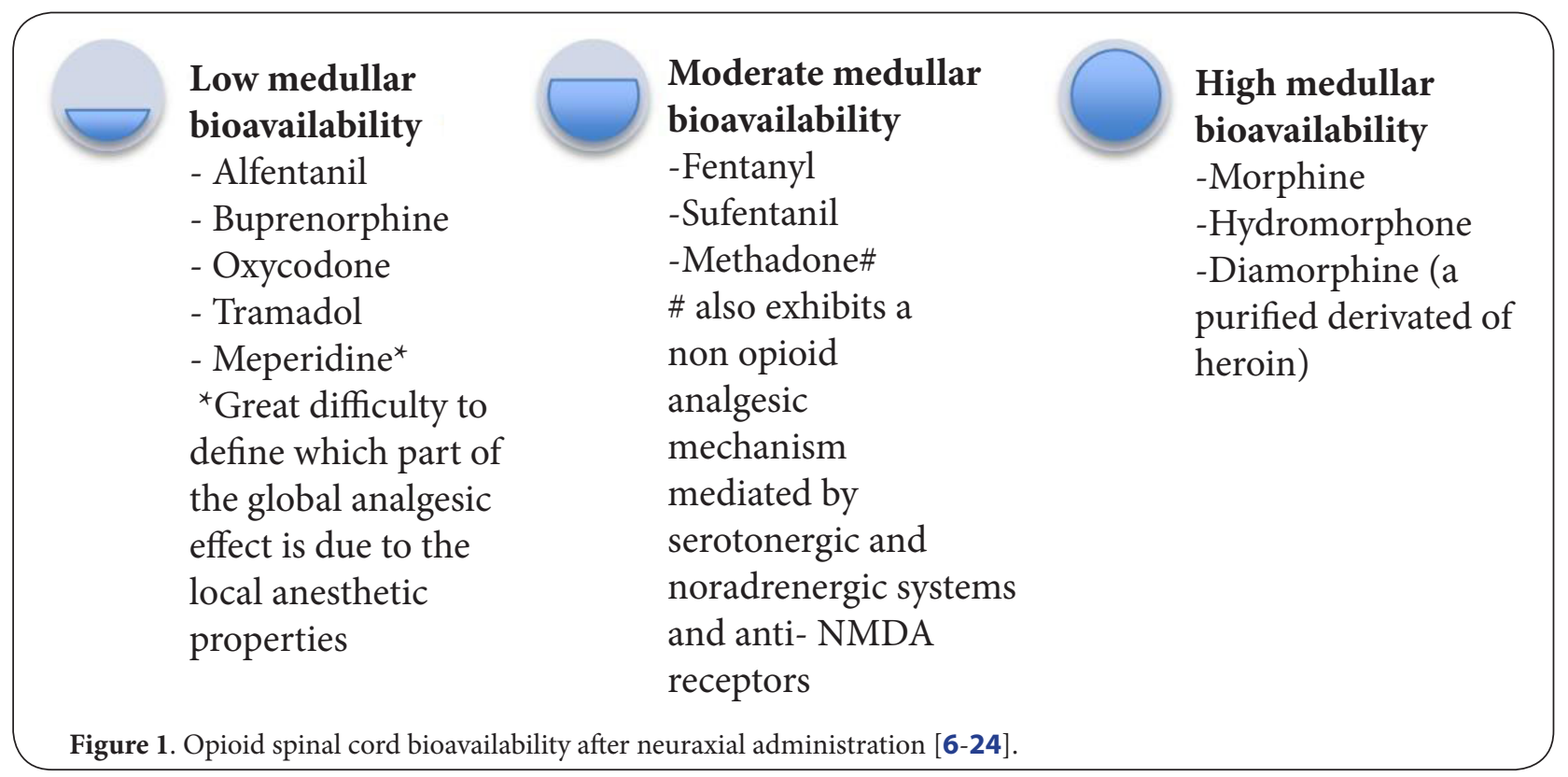

effects of opioids from their dose-limiting side effects. To do so, we must better identify specific opioids and adequate doses and routes of administration (epidural vs. intrathecal) that result in a predominately spinal site of analgesic action rather than a brain one.

Bernards CM [7] carried out a review of experimental studies in animals focusing on the measurement of opioid concentration in the epidural, intradural, spinal cord and perispinal tissues (epidural fat), following spinal injection. These studies characterize, for the first time, the factors governing the rate and extent to which different opioids redistribute from the epidural and intrathecal spaces to reach target opioid receptors in the spinal cord dorsal horn. The findings indicate that increasing lipid solubility decreases the spinal cord bioavailability of spinally administered opioids. The author concluded that spinal opioid administration does not guarantee a spinal site of action and that available animal data clearly demonstrate that the spinal bioavailability of hydrophilic drugs (eg., morphine, diamorphine, hydromorphone) is superior to that of lipophilic opioids (eg., alfentanil, fentanyl, sufentanil) (see Figure 1). These animal data help to explain what multiple trials have demonstrated that is the analgesic effect of spinally administered lipid-soluble opioids is due in part, to uptake into plasma and distribution to brainstem opioid receptors.

The administration of hydrophilic opioids via a continuous infusion results in selective spinal analgesia with a low incidence of side effects. Lipophilic opioids may also be associated with spinal effects. However, the doses required to produce postoperative analgesia also produce plasma concentrations within the MEAC. Thus, in clinical practice it may not be possible to limit epidural doses of lipophilic opioids to those associated with spinal analgesia. Regardless of the mechanism of action, epidural administration of lipophilic opioids may offer no clinical advantages over the IV route. Notwithstanding, epidural administration of small doses of lipophilic opioids in combination with local anesthetics (LA) may offer significant clinical advantages over systemic administration of opioids alone. Consequently, dose-ranging studies will be necessary to determine the ideal concentrations of opioids and LA, as well as the ratios of the two drugs to obtain optimal analgesia with minimal incidence of side effects [8].

The spinal administration of an opioid drug does not guarantee selective action and segmental analgesia in the spine. Evidence from experimental studies in animals indicates that bioavailability in the spinal cord biophase is negatively correlated with liposolubility, and is higher for hydrophilic opioids, such as morphine, than lipophilic opioids, such as fentanyl, sufentanil and alfentanil. Clinical trials have demonstrated that the administration of lipophilic opioids by continuous epidural infusion may not produce analgesia due to a spinal mechanism, although by strengthening local anaesthesia they enable total doses to be reduced. This contrasts with single epidural injections of fentanyl, which with sufficiently high quantities of the opioid can reach specific areas at the spinal level. All opioids administered intrathecally produce part of their analgesic effect via spinal selectivity, although lipophilic opioids can also rapidly reach higher centres of the brain due to their good vascular uptake and redistribution [9].

Fentanyl is the lipophilic opioid on which most studies have been focused concerning its epidural administration, but results remain inconsistent with respect to its spinal 
selectivity. Several studies have demonstrated that the quality of analgesia, the incidence of side effects, daily fentanyl rescue use, and plasma levels after $24 \mathrm{~h}$ of infusion are similar between patients receiving either epidural or IV therapy [10-13]. Moreover, after thoracotomy, thoracic epidural administration of fentanyl confers only marginal benefit over IV or lumbar epidural routes [14]. These data indicate that the mechanism of postoperative fentanyl analgesia after epidural administration could be primarily systemic. However, there also studies [15-18] which suggest that a spinal effect may occur after epidural administration of fentanyl. Indeed some authors have found how fentanyl administered epidurally after cesarean delivery has a primarily spinal mechanism of action and this effect is enhanced by very small dose epidural bupivacaine and epinephrine [19]. However, in this case, the synergism among the 3 administered epidural drugs could explain the best results for the epidural route as it was confirmed by Niemi G et al., in 2 randomized clinical trials after mayor surgery $[20,21]$.

Further, in an experimental pain study in volunteers by Ginosar et al., [22], epidural fentanyl caused segmental analgesia when administered as a bolus and non-segmental systemic analgesia when administered as a continuous infusion. The response to maximum tolerable pain was assessed over 420 min with electric and heat stimuli in two regions, the head and the leg (supraspinal and spinal respectively). Plasma concentrations of fentanyl were measured and found to only reach the MEAC after continuous infusion at high doses. Their findings were mostly in agreement with the previous studies they reviewed and were explained by the higher level of the drug reaching the spinal cord biophase in the bolus group. It has been suggested that this effect is due to the gradient of concentration reached between the epidural and the intrathecal spaces after the administration in boluses and not in continuous infusion. The dose at which fentanyl would produce spinal anaesthesia has been estimated to be around $10 \mu \mathrm{g} / \mathrm{ml}$. Accordingly, if in routine clinical postoperative practice physicians combined this opioid with a continuous infusion of LA at 2-5 $\mu \mathrm{g} / \mathrm{ml}$ doses, what we expect achieve would be an enhancement of the analgesia by decreasing the dose of LA, with a potential systemic effect and, therefore, an additive effect rather than a spinal synergic one [23]. So, these findings may help resolve the long-standing controversy surrounding the site of action of epidural fentanyl but more trials are needed in the future to assess this affirmation.

In relation to this topic, Mather LE \& Cousins MJ, [24] have the opinion that it's sensible not to think of supraspinal and spinal mechanisms in terms of a dichotomy. Despite commentary about lipophilic drugs like fentanyl distributing into epidural fat, countless studies with epidurally injected opioids and LA (remember that fentanyl and bupivacaine have similar physicochemical properties) have demonstrated that systemically absorbed drug has a similar blood concentration profile to that after IM injection. The biphasic absorption patterns found can be interpreted as a "portion" of the dose being absorbed reasonably rapidly with a half-life of around 5 to $10 \mathrm{~min}$, generating the "peak" arterial blood concentration at around 10 min after injection. The remaining "portion," presumably that distributed into fatty tissues, is absorbed more slowly with a half-life of several hours, thereby sustaining the blood drug concentrations compared with IV drug administration. Blood-borne drug will thus be delivered to both supraspinal and spinal receptor sites in proportion to the distribution of cardiac output, in addition to drug delivered by local mechanisms of bulk flow and diffusion. Although the amount of blood-borne drug delivered supraspinally may be small after epidural compared with IV injection, one has to remember, as pointed out in the early days of spinal opioid pharmacology, that the dual spinal and supraspinal opioid actions have a reinforcing action that is relevant both for agonist and antagonism. To the authors, a preferred research plan would be to determine whether an intramuscular injection or an IV infusion designed to mimic the plasma fentanyl concentrations from epidural administration would reproduce the analgesia of epidural administration, but without the side effects.

\section{Clinical practice}

Clinical practice on spinal opioids of worldwide anesthesiologists varies very much in relation to the country selected. Although there is no "ideal analgesic" clinicians alike continue to search for compounds with qualities which may approach this utopic idea. Regional anesthesia is now involved into the multimodal concept for the management of postoperative pain. To reach this objective, a spinal opioid is commonly used alone or plus LA to provide high degree analgesia associated to systemic drugs and also non-pharmacologic and rehabilitation programs [25].

Neuraxial analgesia is often provided using a mixture of LA and opioids, which yield analgesic synergy. In a review on combination opioid analgesics by Smith HS [26], the author concluded that this combination enhance and/or optimize analgesic efficacy and that this synergistic combination of agents provides better pain relief which is generally associated with fewer side effects than when either drug is given alone. Moreover, LA has been shown to alter signalling of other $G$ protein-coupled receptors, but little is known about their effect on opioid receptor signalling. He also added that results from experimental studies suggest that LA decrease opioid inhibition of calcium channel activity by interfering with the GPT-mediated signal transduction between opioid receptors and calcium channels.

In a recent meta-analysis [27] it has been tested whether the intrathecal combination of a reduced dose of LA with an opioid compared with a standard dose of the same LA alone guaranteed adequate intraoperative anesthesia and postoperative analgesia and decreased LA-related adverse effects. 1393 patients from 28 trials were included. In experimental groups, the median decrease in LA doses was $40 \%$ 
(range, 12\%-70\%). With experimental interventions, there was evidence of a reduction in the duration of motor blockade postoperatively (average, -50 minutes), time to discharge from hospital or PACU (-33minutes), time to ambulation (-28minutes), and time to urination (-14minutes). There was also evidence of a decrease in the risk of shivering (risk ratio [RR]: 0.26; 95\% confidence interval [CI]: 0.12-0.56), nausea (RR: $0.45 ; 95 \% \mathrm{Cl}: 0.31-0.66$ ), and arterial hypotension (RR: $0.52 ; 95 \% \mathrm{Cl}: 0.35-0.78)$. The risk of pruritus was increased (RR: $11.7 ; 95 \% \mathrm{Cl}: 6.2-21.9$ ). The authors concluded that adding an opioid to a reduced dose of an intrathecal LA could decrease LA-related adverse effects and improve recovery from the spinal block without compromising intraoperative anesthesia or duration of postoperative analgesia.

\section{Type of opioid used in postoperative pain Morphine}

It was the first opioid approved by the US Food and Drugs Administration (FDA) for spinal administration and it's the epidural opioid that has been the most widely used and with which others are compared [9]. Indeed, it could be considered the "gold standard" of spinal drugs, which does not always imply the ideal one, as due to its spinal cord selectivity, the dose required is much lower for epidural than for parenteral administration based on it presents the best spinal bioavailability [6-9]. It can be administered as a bolus $(30-100 \mu \mathrm{g} /$ $\mathrm{kg}$ ) or as continuous infusion (0.2-0.4 mg/h), which seems to induce better quality analgesia, and alone or together with $L A$, as synergy between the drugs increases the overall analgesic effect $[\mathbf{8 , 9 , 2 8}$. In addition, controlled clinical trials in either hip or knee replacement surgery, abdominal surgery, spine surgery and caesarean sections [29-35] have demonstrated that a single-dose EREM (Extended Released Epidural Morphine) can provide up to 48 hours very good quality of postoperative analgesia with an acceptable and predictable side effect profile (recommended dose $<15 \mathrm{mg}$ ). Prophylactic analgesia with EREM leads to a more satisfactory patient experience than IV opioid PCA (Patient Controlled Analgesia).

EREM was approved in 2004 by the FDA intended for singledose administration by epidural route at the lumbar level, with mean duration of action of $48 \mathrm{~h}$ after a single injection use and delaying the peak concentration in the CSF until 3 hours after injection, without the problems associated with the catheter and with the expectation of improving on the overall failure rate with continuous epidural infusion technique which is estimated to be around $30 \%$. The formulation must not be injected through a filter as the particles may be disrupted. The basic points for its use include administration prior to surgery or after clamping the umbilical cord during a caesarean section and at least 15 minutes after the epidural test dose of LA and that no more epidural drugs be given for $48 \mathrm{~h}$, since the continuous infusion of LA increase the release of morphine [36]. This advertence is due to a potential physicochemical interaction between epidural LA and EREM, which could negate the sustained release [37]. It was observed how a large dose of epidural lidocaine 1 hour before EREM administration alters the pharmacokinetics and drug effects of EREM. There was an increased incidence in vomiting, oxygen use, and hypotension in patients who received $20-35 \mathrm{ml}$ lidocaine before $8 \mathrm{mg}$ EREM. So the authors concluded that clinicians must apply caution when EREM is administered even 1 hour after an epidural lidocaine "top-up" for cesarean delivery [37].

As with all opioids, the chief hazard is respiratory depression especially in elderly and debilitated patients and in those with compromise respiratory function. In a meta-analysis on the risk of respiratory depression compared to intravenous morphine $\mathrm{PCA}$, an odds ratio (OR) of $5.80(95 \% \mathrm{Cl} 1.05-31.93$; $p=0.04$ ) was estimated for the use of EREM [33]. There are no description data to guide the treatment of a patient who receives intrathecal EREM, but it has been described a case of accidental spinal injection of $7.5 \mathrm{mg}$ EREM in a 45-yr-old women under a exploratory laparotomy, which was successfully treated without postoperative artificial ventilation, using a IV naloxone infusion $(40-140 \mu \mathrm{g} / \mathrm{h})$ during $22 \mathrm{~h}$ until the patient reported any pain [38].

In a meta-analysis of randomized trials over patients undergoing major surgery under general anaesthesia and receiving systemic opioids for break-through pain after operation [39], the additional use of intrathecal morphine decreased pain intensity, and also systemic morphine consumption, but does not decrease the risk of morphinerelated adverse effects. The postoperative morphine-sparing effect was significantly weaker in patients undergoing cardiothoracic compared with abdominal surgery and the authors also concluded that we still do not know the optimal dose of intrathecal morphine when used alone. Nevertheless, in a meta-analysis based on studies on spinal anaesthesia [40], with morphine as adjuvant of an LA without general anaesthesia, the rate of adverse effects of intrathecal morphine was analysed $(n=790)$, compared to placebo $(n=524)$ and a relationship was found between the dose of drug used and the occurrence of the adverse effects. The authors concluded that the use of intrathecal morphine at doses $<300 \mu \mathrm{g}$, although associated with a higher rate of adverse effects, is a safe dose, since among those on this dose the rate of episodes of respiratory depression was not higher than among the placebo group who received systemic opioids. In another recent meta-analysis, [41] about opioids added to LA for single-shot intrathecal anaesthesia in patients undergoing minor surgery, morphine (0.05-2 $\mathrm{mg})$ and fentanyl $(10-50 \mu \mathrm{g})$ added to bupivacaine were the most frequently tested. Duration of postoperative analgesia was prolonged either with morphine (315 to 641 min) or fentanyl (60 to $168 \mathrm{~min}$ ).

Morphine could be the most suitable opioid for neuraxial administration in the context of acute postoperative pain because provides a very good quality of epidural and intrathecal analgesia, but its long elimination time and its potential to cause delayed adverse effects, limit its routine use and 
require careful selection of patients and vigilance protocols, and it's not recommended for ambulatory patients [36]. The optimal neuraxial opioid dose is a balance between the conflicting demands of providing optimal analgesia while minimizing dose-related adverse effects. The optimal "single shot" intrathecal morphine dose appears to be 75-150 $\mu \mathrm{g}$ and the ideal "single shot" epidural morphine dose could be 2.5-3.75 mg, for the first 24 hours after surgery [42].

\section{Fentanyl and sufentanil}

The most lipophilic opioids such as fentanyl and sufentanil are the opioids most studied and widely used epidural and intradurally in the context of postoperative pain given their rapid onset of action (10-15 $\mathrm{min}$ ) and their short duration (2-5 h) [36]. Several studies have focused on demonstrating the beneficial effect of the combination of lipophilic opioids with LA in ambulatory surgery and in the field of obstetrics as analgesic agents for labour pain [43]. In this way, the combination of intrathecal fentanyl (20-30 $\mu \mathrm{g})$ or sufentanil $(5-7.5 \mu \mathrm{g})$ with bupivacaine or lidocaine leads to a faster onset of blockade and better intraoperative and immediate postoperative analgesia without increasing the degree of motor blockade or the time until discharge [44].

\section{Hydromorphone}

It's a hydrogenated ketone of morphine and was first synthesised in Germany in 1921. Epidurally, it has an equianalgesic dose ratio of 1:2 compared to its parenteral administration and the recommendable dose is $10-20 \mu \mathrm{g} / \mathrm{kg}$. It could have several potential advantages over morphine for its use as PCEA (patient-controlled epidural analgesia): it has intermediate solubility (octanol buffer distribution coefficient of 525 vs. 1 for morphine), with a rapid onset of action (5-10 min), moderate duration of action (effective duration of action of 4-6 h) and very low risk of delayed respiratory depression, as well as a higher potency administered epidurally (3:1 by infusion increasing to $5: 1$ by bolus) [9]. A recent study has demonstrated its effectiveness in 3736 patients after lower limb orthopaedic surgery as patient-controlled epidural anaesthesia at a dose of $10 \mu \mathrm{g} / \mathrm{ml}$, in combination with $0.06 \%$ bupivacaine [45]. To routinely use this drug epidurally, these results must be confirmed in major thoraco-abdominal surgery, since the limited data published on this topic to date are restricted to paediatric surgery using boluses or minor abdominal surgery, such as prostatectomy or caesarean section surgery [46].

\section{Methadone}

This is an opioid considered to provide moderate spinal analgesia, but its long duration of action may result in plasma accumulation and supraspinal adverse effects. Its mechanism of action is mediated by the endogenous opioid, serotonergic and noradrenergic systems, and also by NMDA receptor antagonists. Otherwise, in comparison with morphine, it has a weaker potency and does not have active metabolites, so it's not accumulated in patients with renal failure [9]. In patients undergoing abdominal or lower limb surgery, it has been confirmed that the continuous epidural infusion (3-6 $\mathrm{mg}$ bolus + 6-12 mg infusion/24 h) produced lower plasma concentrations than the administration in epidural boluses (3-6 mg/8 h) with a lower rate of miosis, no cumulative effect and similar good pain relief in both groups, during the 3 days of treatment [47]. In a patient-controlled postoperative analgesia clinical trial after thoracic surgery it was more effective using methadone epidurally than intravenously with the total amount of methadone used of $18 \mathrm{mg} /$ day by the epidural route compared to $24 \mathrm{mg} /$ day by intravenous one [48]. Another trial using methadone as a sole agent for postoperative post-thoracotomy pain, showed that this route of administration was effective for postoperative analgesia but with a higher rate of pruritus, vomiting and urinary retention versus epidural bupivacaine or clonidine. Patients in the methadone group received an initial dose of $6 \mathrm{mg}$ in $10 \mathrm{ml}$ saline given over $20 \mathrm{~min}$ followed immediately by infusion of $0.5 \mathrm{mg} / \mathrm{h} \mathrm{[49]}$.

\section{Diamorphine}

This is a purified derivative of heroin (diacetylmorphine). It's considered a pro-drug that lacks intrinsic opioid activity, but as it is quickly metabolised by esterases into neural tissue, it is transformed into the active ingredients 6-acetylmorphine and morphine. Its clinical practice is justified by potential advantages of diamorphine with respect to morphine, due to its higher liposolubility (octanol-water partition coefficient of 280 compared to 1.4 for morphine), which means that it has a rapid onset of action and a lower effective duration of action together with a better profile of adverse effects, without risk of delayed respiratory depression [9]. In a recent survey it was the opioid most commonly used intrathecally in the United Kingdom (UK), especially in the obstetric area. $78.2 \%$ of anaesthetic units used it regularly, followed closely by fentanyl (74.1\%), and finally morphine was less commonly used (21.3\%) at reported doses of $0.2-0.5 \mathrm{mg}, 12.5-25 \mu \mathrm{g}$ and 0.1-0.5 mg respectively [50].

\section{Pethidine (Meperidine)}

It's use has been well described in Australian and New Zealand practice, particularly in the field of obstetric anaesthesia. Reported methods of delivery have included bolus injection, continuous infusion and patient-controlled epidural analgesia for the treatment of postoperative and labour pain. Because of its intermediate lipid solubility (525), pethidine may have advantages over other epidural opioids however potential for accumulation of its excitatory metabolite norpethidine limits its use to relatively short durations of treatments [51].

\section{Buprenorphine}

This drug is a lipophilic partial agonist with a higher affinity on specific opioid receptors and higher potency than morphine 


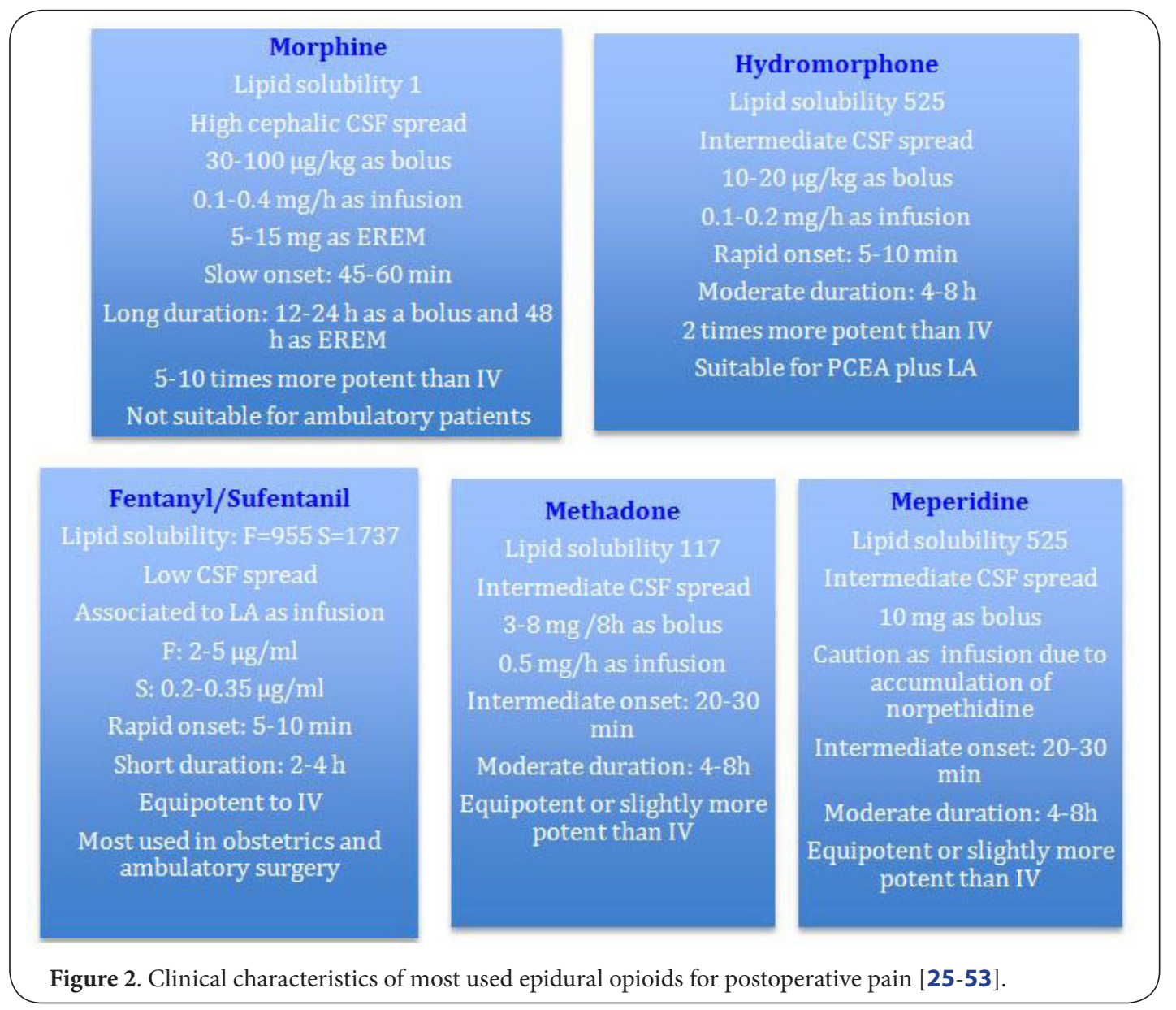

after systemic administration. After epidural administration similar maximal concentrations are reached both in plasma and CSF, at 10 and $30 \mathrm{~min}$, respectively and, therefore, it can cause early respiratory depression (within $30 \mathrm{~min}$ ) that can be resistant to naloxone [9]. Its better characteristics in terms of adverse effects have meant that it is still used clinically, especially in Asian countries, and its effectiveness epidurally has been confirmed at doses of $200 \mu \mathrm{g}$ injected at two cephalic levels above the surgical incision after lumbar spine surgery in patients given general anaesthesia [52], as well as in caesarean sections at doses of $300 \mu \mathrm{g}$ epidurally, with the same analgesic quality and, therefore, the same power as the intradural dose of $150 \mu \mathrm{g}$ [53].

Most common epidural opioids properties are summarized in Figure 2.

\section{Recommendations for correct opioid selection Multimodal postoperative analgesia}

It is important to highlight that the treatment of postoperative acute pain requires a multimodality approach, whenever possible combining regional anaesthesia, analgesics that act centrally like paracetamol, others drugs that have a peripheral non steroidal anti-inflammatory effect (classic
NSAID or selective ciclooxigenase-2 inhibitors), and opioids using different routes of administration, as well as coadjutant drugs, such as those for neuropathic pain like gabapentin or pregabalin and the N-methyl-D-aspartate antagonists. Moreover, spinal opioids should not be administered as a unique analgesic technique and would be included into a wider analgesic planning based on the previous experience of the medical team, the risk/benefit balance for the patient and indeed the hospital setting [54].

Prospect group (Procedure Specific Postoperative Pain Management: http://www.postoppain.org)

In the present days, optimal analgesia should be based on clinical evidence for each surgical procedure and should be combined with physiotherapy and rehabilitation programmes in order to minimise the period of postoperative recovery, hospital stay and convalescence of our patients. The PROSPECT group helps the physicians to choose the most adequate drugs and techniques combination based on the medical published evidence. Very detailed evidence related to procedurespecific postoperative pain management is provided by the PROSPECT group. Recommendations are based on a systematic evaluation of RCTs of procedure-specific data supplemented 
by evidence transferred from studies of procedures thought to have a similar pain profile, as well as information from clinical practice. Recommendations are then made for pre, intra and postoperative pain management [55].

\section{An update report by the american society of anesthesiologist task force on acute pain management}

Practice Guidelines are systematically developed recommendations that assist the practitioner and patient in making decisions about health care. These recommendations may be adopted, modified, or rejected according to clinical needs and are not intended to replace local institutional policies. In addition, Practice Guidelines developed by the American Society of Anesthesiologists (ASA) are not intended as standards or absolute requirements, and their use cannot guarantee any specific outcome. Practice Guidelines are subject to revision as warranted by the evolution of medical knowledge, technology, and practice. They provide basic recommendations that are supported by a synthesis and analysis of the current literature, expert and practitioner opinion, open forum commentary, and clinical feasibility data. This document updates the "Practice Guidelines for Acute Pain Management in the Perioperative Setting: An Updated Report by the American Society of Anesthesiologists Task Force on Acute Pain Management," adopted by the ASA in 2003 and published in 2004.

Overall recommendations conclude that perioperative techniques should include but not are limited to various analgesic modalities such as central neuraxial opioid analgesia, PCA with systemic opioids and peripheral regional analgesic blockades [28].

Practice guidelines for the management of respiratory depression associated with neuraxial opioid administration The most feared complication of opioid administration is respiratory depression. The incidence is infrequent for doses commonly used clinically but it's dose-dependent for both hydrophilic and lipophilic opioids. The incidence of respiratory depression associated with continuous epidural infusions containing opioids has been estimated from large observational studies, ranging from $0.09 \%$ to $0.4 \%$. Overall risk of respiratory depression after intrathecal o epidural opioids is less than $1 \%$, and limited data suggest that it's similar to that of opioids delivered via parenteral route [36].

These are the recommendations from an update report made by the American Society of Anesthesiologists (ASA) Task Force on neuraxial opioids [56]:

1. Prevention of respiratory depression after neuraxial opioid administration:

-Particular attention should be direct toward signs,

symptoms, or a history of sleep apnea, coexisting diseases or conditions (eg., diabetes, obesity), current medications (including preoperative opioids), and adverse effects after previous opioid administration.
- Patients with a history of sleep apnea treated with noninvasive positive airway pressure should be encouraged to bring their own equipment to the hospital.

\section{- Drug selection:}

-Single-injection neuraxial opioids may be safely used in place of parenteral opioids without altering the risk of respiratory depression or hypoxemia.

-Single-injection neuraxial fentanyl or sufentanil may be safe alternatives to a single-injection of neuraxial morphine.

-When clinically suitable, extended-release epidural epidural morphine may be used in place of intravenous or conventional (i.e., immediate-release) epidural morphine, although extended monitoring may be required. -Continuous epidural opioids are preferred to parenteral opioids for anaesthesia and analgesia for reducing the risk of respiratory depression.

-When clinically suitable, appropriate doses of continuous epidural infusion of fentanyl or sufentanil may be used in place of continuous infusion of morphine or hydromorphone without increasing the risk of respiratory depression.

-Neuraxial morphine or hydromorphone should not be given to outpatient surgical patients.

\section{- Dose selection:}

- The lowest efficacious dose of neuraxial opioids should be administered to minimize the risk of respiratory depression.

-Parenteral opioids or hypnotics should be cautiously administered in the presence of neuraxial opioids. -The concomitant administration of neuraxial opioids and parenteral opioids, sedatives, hypnotics, or magnesium requires increasing monitoring (eg., intensity, duration or additional methods).

\section{Detection of respiratory Depression:}

All patients receiving neuraxial opioids should be monitored for adequacy of ventilation (eg., respiratory rate, depth of respiration assessed without disturbing a sleeping patient), oxygenation (eg., pulse-oximetry when appropriate), and level of consciousness.

When hydrophilic opioids are used as a bolus, monitoring at last once every hour should be performed for the first 12 hours after initiation, followed by monitoring at last once every 2 hours for the next 12 hours. After 24 hours, monitoring should be performed at last once every 4 hours for a minimum of 48 hours. For lipophilic opioids as a single bolus continual monitoring should be performed for the first 20 minutes after administration followed by monitoring al least once per hour until 2 hours has passed. After $2 \mathrm{~h}$ for lipophilic opioids and $24 \mathrm{~h}$ for hydrophilic ones, frequency of monitoring should be dictated by patient's overall clinical condition and concurrent medications. Monitoring should be performed during the entire time if an infusion is in use in both cases. 


\section{Expert's opinion and personal experience}

Arriving to this point may be possible that the final decision for proper choice of spinal opioid analgesic drug or combination could be difficult in our clinical practice or procedure. In this case, the final recommendation must be based on expert's opinions and case reports articles. Moreover, the therapy selected should reflect the individual anesthesiologist's expertise, as well as the capacity for safe application of the modality in each practice setting.

\section{Conclusions}

Opioids are the most potent centrally acting analgesic drugs for the treatment of pain. On the recent years, since the discovery of spinal opioid receptors, the use of spinal opioids has been adopted in clinical practice in the hope of producing intense segmental analgesia that was devoid of the dose-limiting side effects associated with systemic opioid administration. Experimental and clinical studies have demonstrated that after their neuraxial administration, liposolubility is inversely proportional to their spinal selectivity, which is higher for morphine, than for other more lipophilic drugs, such as fentanyl and sufentanil.

In recent years, more information has been available regarding the use of spinal opioids alone or in combination with $L A$, which has helped us to define the clinical applicability and efficacy of these forms of therapy and has also contributed to the understanding of the disadvantages of their use. This knowledge could be used to select a treatment based on patient's particular needs and personal physician experience in the perioperative setting in order to produce a high quality pain control combined with a low incidence of adverse effects, but this decision should be pivot on published medicine evidence data.

Finally, physicians should reach a consensus on this topic and an international protocol should be adopted for proper patients monitoring after spinal opioids administration to avoid the feared respiratory depression and also other minor adverse effects.

\section{Competing interest}

The author declares that he has no competing interests.

Publication history

EIC: D. John Doyle, Case Western Reserve University, USA.

Received: 09-Jun-13 Revised: 21-Jun-2013

Accepted: 20-Sep-2013 Published: 01-Oct-2013

\section{References}

1. Bernards $\mathrm{CM}$. Sophistry in medicine: lessons from the epidural space. Reg Anesth Pain Med. 2005; 30:56-66. | Article | PubMed

2. Brill S, Gurman GM and Fisher A. A history of neuraxial administration of local analgesics and opioids. Eur J Anaesthesiol. 2003; 20:682-9. | Article | PubMed

3. Yaksh TL and Rudy TA. Analgesia mediated by a direct spinal action of narcotics. Science. 1976; 192:1357-8. | Article | PubMed
4. Wang JK, Nauss LA and Thomas JE. Pain relief by intrathecally applied morphine in man. Anesthesiology. 1979; 50:149-51. | Article | PubMed

5. Behar M, Magora F, Olshwang D and Davidson JT. Epidural morphine in treatment of pain. Lancet. 1979; 1:527-9. | Article | PubMed

6. Bernards $\mathrm{CM}$. Understanding the physiology and pharmacology of epidural and intrathecal opioids. Best Pract Res Clin Anaesthesiol. 2002; 16:489-505. | Article | PubMed

7. Bernards $\mathrm{CM}$. Recent insights into the pharmacokinetics of spinal opioids and the relevance to opioid selection. Curr Opin Anaesthesiol. 2004; 17:441-7. | Article | PubMed

8. Bujedo BM. Spinal Opioid Bioavailability in Postoperative Pain. Pain Pract. 2013. | Article | PubMed

9. Bujedo BM, Santos SG and Azpiazu AU. A review of epidural and intrathecal opioids used in the management of postoperative pain. $J$ Opioid Manag. 2012; 8:177-92. | PubMed

10. Glass PS, Estok P, Ginsberg B, Goldberg JS and Sladen RN. Use of patientcontrolled analgesia to compare the efficacy of epidural to intravenous fentanyl administration. Anesth Analg. 1992; 74:345-51. | Article | PubMed

11. Sandler AN, Stringer D, Panos L, Badner N, Friedlander M, Koren G, Katz J and Klein J. A randomized, double-blind comparison of lumbar epidural and intravenous fentanyl infusions for postthoracotomy pain relief. Analgesic, pharmacokinetic, and respiratory effects. Anesthesiology. 1992; 77:626-34. | Article | PubMed

12. Loper KA, Ready LB, Downey M, Sandler AN, Nessly M, Rapp S and Badner N. Epidural and intravenous fentanyl infusions are clinically equivalent after knee surgery. Anesth Analg. 1990; 70:72-5. | Article | PubMed

13. Ellis DJ, Millar WL and Reisner LS. A randomized double-blind comparison of epidural versus intravenous fentanyl infusion for analgesia after cesarean section. Anesthesiology. 1990; 72:981-6. | Article | PubMed

14. Guinard JP, Mavrocordatos P, Chiolero R and Carpenter RL. A randomized comparison of intravenous versus lumbar and thoracic epidural fentanyl for analgesia after thoracotomy. Anesthesiology. 1992; 77:1108-15. | Article | PubMed

15. Coda BA, Brown MC, Schaffer R, Donaldson G, Jacobson R, Hautman $B$ and Shen DD. Pharmacology of epidural fentanyl, alfentanil, and sufentanil in volunteers. Anesthesiology. 1994; 81:1149-61. | Article PubMed

16. Salomaki TE, Laitinen JO and Nuutinen LS. A randomized double-blind comparison of epidural versus intravenous fentanyl infusion for analgesia after thoracotomy. Anesthesiology. 1991; 75:790-5. | Article I PubMed

17. Welchew EA and Breen DP. Patient-controlled on-demand epidural fentanyl. A comparison of patient-controlled on-demand fentanyl delivered epidurally or intravenously. Anaesthesia. 1991; 46:438-41. | Article I PubMed

18. Grant RP, Dolman JF, Harper JA, White SA, Parsons DG, Evans KG and Merrick CP. Patient-controlled lumbar epidural fentanyl compared with patient-controlled intravenous fentanyl for post-thoracotomy pain. Can J Anaesth. 1992; 39:214-9. | Article | PubMed

19. Cohen S, Pantuck CB, Amar D, Burley E and Pantuck EJ. The primary action of epidural fentanyl after cesarean delivery is via a spinal mechanism. Anesth Analg. 2002; 94:674-9. | Article | PubMed

20. Niemi $G$ and Breivik H. Epinephrine markedly improves thoracic epidural analgesia produced by a small-dose infusion of ropivacaine, fentanyl, and epinephrine after major thoracic or abdominal surgery: a randomized, double-blinded crossover study with and without epinephrine. Anesth Analg. 2002; 94:1598-605. | Article | PubMed

21. Niemi $G$ and Breivik $H$. The minimally effective concentration of adrenaline in a low-concentration thoracic epidural analgesic infusion of bupivacaine, fentanyl and adrenaline after major surgery. A randomized, double-blind, dose-finding study. Acta Anaesthesiol Scand. 2003; 47:439-50. | Article | PubMed 
22. Ginosar Y, Riley ET and Angst MS. The site of action of epidural fentany in humans: the difference between infusion and bolus administration. Anesth Analg. 2003; 97:1428-38. | Article | PubMed

23. George MJ. The site of action of epidurally administered opioids and its relevance to postoperative pain management. Anaesthesia. 2006; 61:659-64. | Article | PubMed

24. Mather LE and Cousins MJ. The site of action of epidural fentanyl: what can be learned by studying the difference between infusion and bolus administration? The importance of history, one hopes. Anesth Analg. 2003; 97:1211-3. | Article | PubMed

25. Mugabure Bujedo B, Tranque Bizueta I, Gonzalez Santos S and Adrian Garde R. [Multimodal approaches to postoperative pain management and convalescence]. Rev Esp Anestesiol Reanim. 2007; 54:29-40. | PubMed

26. Smith HS. Combination opioid analgesics. Pain Physician. 2008; 11:20114. | Article | PubMed

27. Popping DM, Elia N, Wenk M and Tramer MR. Combination of a reduced dose of an intrathecal local anesthetic with a small dose of an opioid: a meta-analysis of randomized trials. Pain. 2013; 154:1383-90. | Article I PubMed

28. Practice guidelines for acute pain management in the perioperative setting: an updated report by the American Society of Anesthesiologists Task Force on Acute Pain Management. Anesthesiology. 2012; 116:24873. | Article | PubMed

29. Alam $M$ and Hartrick CT. Extended-release epidural morphine (DepoDur): an old drug with a new profile. Pain Pract. 2005; 5:349-53. | Article | PubMed

30. Gambling D, Hughes T, Martin G, Horton W and Manvelian G. A comparison of Depodur, a novel, single-dose extended-release epidural morphine, with standard epidural morphine for pain relief after lower abdominal surgery. Anesth Analg. 2005; 100:1065-74. | Article | PubMed

31. Viscusi ER. Emerging techniques in the management of acute pain: epidural analgesia. Anesth Analg. 2005; 101:S23-9. | Article | PubMed

32. Hartrick CT and Hartrick KA. Extended-release epidural morphine (DepoDur): review and safety analysis. Expert Rev Neurother. 2008; 8:1641-8. | Article | PubMed

33. Sumida S, Lesley MR, Hanna MN, Murphy JD, Kumar K and Wu CL. Metaanalysis of the effect of extended-release epidural morphine versus intravenous patient-controlled analgesia on respiratory depression. J Opioid Manag. 2009; 5:301-5. | PubMed

34. Offley SC, Coyne E, Horodyski M, Rubery PT, Zeidman SM and Rechtine GR. Randomized trial demonstrates that extended-release epidural morphine may provide safe pain control for lumbar surgery patients. Surg Neurol Int. 2013; 4:S51-7. | Article | PubMed Abstract | PubMed Full Text

35. Mhuircheartaigh RJ, Moore RA and McQuay HJ. Analysis of individual patient data from clinical trials: epidural morphine for postoperative pain. Br J Anaesth. 2009; 103:874-81. | Article | PubMed

36. Mugabure Bujedo B. A clinical approach to neuraxial morphine for the treatment of postoperative pain. Pain Res Treat. 2012; 2012:612145. I Article | PubMed Abstract | PubMed Full Text

37. Atkinson Ralls L, Drover DR, Clavijo CF and Carvalho B. Prior epidural lidocaine alters the pharmacokinetics and drug effects of extendedrelease epidural morphine (DepoDur(R)) after cesarean delivery. Anesth Analg. 2011; 113:251-8. | Article | PubMed

38. Gerancher JC and Nagle PC. Management of accidental spinal administration of extended-release epidural morphine. Anesthesiology. 2008; 108:1147-9; discussion 1149. | Article | PubMed

39. Meylan N, Elia N, Lysakowski C and Tramer MR. Benefit and risk of intrathecal morphine without local anaesthetic in patients undergoing major surgery: meta-analysis of randomized trials. Br J Anaesth. 2009; 102:156-67. | Article | PubMed

40. Gehling $M$ and Tryba M. Risks and side-effects of intrathecal morphine combined with spinal anaesthesia: a meta-analysis. Anaesthesia. 2009;
64:643-51. | Article | PubMed

41. Popping DM, Elia N, Marret E, Wenk M and Tramer MR. Opioids added to local anesthetics for single-shot intrathecal anesthesia in patients undergoing minor surgery: a meta-analysis of randomized trials. Pain. 2012; 153:784-93. | Article | PubMed

42. Sultan P, Gutierrez MC and Carvalho B. Neuraxial morphine and respiratory depression: finding the right balance. Drugs. 2011; 71:180719. | Article | PubMed

43. Hamber EA and Viscomi CM. Intrathecal lipophilic opioids as adjuncts to surgical spinal anesthesia. Reg Anesth Pain Med. 1999; 24:255-63. I Article I PubMed

44. Rathmell JP, Lair TR and Nauman B. The role of intrathecal drugs in the treatment of acute pain. Anesth Analg. 2005; 101:S30-43. | Article | PubMed

45. Liu SS, Bieltz M, Wukovits B and John RS. Prospective survey of patientcontrolled epidural analgesia with bupivacaine and hydromorphone in 3736 postoperative orthopedic patients. Reg Anesth Pain Med. 2010; 35:351-4. | Article | PubMed

46. Mulroy MF. Epidural hydromorphone: a step closer to the view from the top. Reg Anesth Pain Med. 2010; 35:333-4. | Article | PubMed

47. Prieto-Alvarez P, Tello-Galindo I, Cuenca-Pena J, Rull-Bartomeu M and Gomar-Sancho $C$. Continuous epidural infusion of racemic methadone results in effective postoperative analgesia and low plasma concentrations. Can J Anaesth. 2002; 49:25-31. | Article | PubMed

48. Parramon F, Garcia C, Gambus P, Vilaplana J, Aragones N and Villalonga A. [Postoperative patient-controlled analgesia is more effective with epidural methadone than with intravenous methadone in thoracic surgery]. Rev Esp Anestesiol Reanim. 2003; 50:326-31. I PubMed

49. Matot I, Drenger B, Weissman C, Shauli A and Gozal Y. Epidural clonidine, bupivacaine and methadone as the sole analgesic agent after thoracotomy for lung resection. Anaesthesia. 2004; 59:861-6. | Article | PubMed

50. Giovannelli $M$, Bedforth $N$ and Aitkenhead A. Survey of intrathecal opioid usage in the UK. Eur J Anaesthesiol. 2008; 25:118-22. | Article | PubMed

51. Ngan Kee WD. Epidural pethidine: pharmacology and clinical experience. Anaesth Intensive Care. 1998; 26:247-55. | PubMed

52. Hashimoto K, Monma F, Amagasa M and Seo N. [Prospective study on anesthesia for lumbar spine surgery--the effectiveness of the perioperative epidural anesthesia with buprenorphine]. Masui. 2009; 58:708-12. | PubMed

53. Ipe S, Korula S, Varma S, George GM, Abraham SP and Koshy LR. A comparative study of intrathecal and epidural buprenorphine using combined spinal-epidural technique for caesarean section. Indian J Anaesth. 2010; 54:205-9. | Article | PubMed Abstract | PubMed Full Text

54. Buvanendran A and Kroin JS. Multimodal analgesia for controlling acute postoperative pain. Curr Opin Anaesthesiol. 2009; 22:588-93. | Article | PubMed

55. Kehlet $\mathrm{H}$, Wilkinson RC, Fischer HB and Camu F. PROSPECT: evidencebased, procedure-specific postoperative pain management. Best Pract Res Clin Anaesthesiol. 2007; 21:149-59. | Article | PubMed

56. Horlocker TT, Burton AW, Connis RT, Hughes SC, Nickinovich DG, Palmer $\mathrm{CM}$, Pollock JE, Rathmell JP, Rosenquist RW, Swisher JL and Wu CL. Practice guidelines for the prevention, detection, and management of respiratory depression associated with neuraxial opioid administration. Anesthesiology. 2009; 110:218-30. | Article | PubMed

\section{Citation:}

Mugabure BB. Recommendations for spinal opioids clinical practice in the management of postoperative pain. J Anesthesiol Clin Sci. 2013; 2:28. http://dx.doi.org/10.7243/2049-9752-2-28 